\title{
KAJIAN USAHA PUKAT CINCIN (PURSE SEINE) BERBASIS PENDARATAN DI MALUKU TENGAH
}

\author{
Ralph Thomas Mahulette ${ }^{1)}$ dan Wijopriono ${ }^{2)}$ \\ 1) Peneliti pada Pusat Riset Perikanan Tangkap, Ancol-Jakarta \\ 2) Peneliti pada Balai Riset Perikanan Laut, Muara Baru-Jakarta \\ Teregristrasi I tanggal: 4 Nopember 2008; Diterima setelah perbaikan tanggal: 20 Pebruari 2009; \\ Disetujui terbit tanggal: 31 Maret 2009
}

\begin{abstract}
Penelitian terhadap perikanan pukat cincin di Maluku Tengah telah dilakukan pada tujuan mengkaji faktor-faktor produksi yang berpengaruh dan menetapkan strategi pengembangan usaha. Data primer dikumpulkan melalui wawancara dengan pelaku atau nelayan dan pengusaha menggunakan kuesioner, sedangkan data sekunder di dapat langsung dari kantor Dinas Perikanan dan Kelautan, Pelabuhan Perikanan Nusantara. Hubungan antara faktor-faktor produksi dan produksi direpresentasikan sebagai fungsi Cob Douglass. Kelayakan usaha dievaluasi berdasarkan pada analisis SWOT. Hasil penelitian menunjukkan bahwa ukuran kapal, anak buah kapal, ukuran alat tangkap, dan harga bahan bakar minyak, sangat berpengaruh terhadap produksi tangkapan. Peluang bagi perkembangan produksi adalah masuknya para investor baru. Strategi alternatif untuk pengembangan perikanan pukat cincin dikaji dan dibahas dalam tulisan ini.
\end{abstract}

KATA KUNCl: $\quad$ kajian usaha, pukat cincin, perairan Maluku Tengah

ABSTRACT: Feasibility assessment of purse seine being based on landing in central Mollucas. By: Ralph Thomas Mahulette and Wijopriono

Research on the purse seine fishery has been done in Central Mollucas, aiming at assessing production factors that influenced fish catch and defined development strategies for the fishery. Primary data was collected through interview by using questionnaire, while secondary data was collected from the Marine Affair and Fisheries Service and also from Fishing Port in Ambon. Relationships between production factors and fish catch represented as mathematical function of Cob Douglass. Business feasibility was evaluated using SWOT analysis. Results of study showed that vessel size, crews, fishing gear size, and fuel consumption were significantly influenced the fish catch. The opportunity for development of the fishery is coming from settlement of new investment. Alternative strategies for developing purse seine fishery were assessed and discussed in this paper.

KEYWORDS: feasibility assessment, purse seine fishery, Central Mollucas waters 


\section{PENDAHULUAN}

Wilayah perairan kodya Ambon Maluku Tengah, yang luasnya hanya $61 \mathrm{~km}^{2}$, tidak dapat dipisahkan dari Laut Banda yang memiliki sifat oseanografi, topografis, dan biologis tersendiri dari wilayah perairan lainnya di Indonesia, di mana potensi sumber daya perikanan yang terkandung di dalamnya cukup tinggi. Laut Banda diduga memiliki cadangan ikan tuna dan cakalang yang terbesar di kawasan Asia-Pasifik (Zen, 1981 dalam Latumeten 1984). Kondisi perairan yang demikian, memberikan kemungkinan yang luas untuk pengembangan usaha perikanan, karena tidak terbatas pada lahan perairan seluas $61 \mathrm{~km}^{2}$.

Perikanan tangkap di Maluku Tengah merupakan usaha yang berpotensi dibandingkan dengan sub sektor lainnya, mengingat laut lebih luas dari daratan. Pada tahun 2005 jumlah hasil tangkapan perairan bagian selatan Pulau Ambon-Laut Banda mencapai 444,5 ton per bulan untuk ikan pelagis kecil dan 183,2 ton per bulan ikan pelagis besar. Sejauh ini tingkat pemanfaatan sumber daya ikan pelagis di wilayah ini baru mencapai $59 \%$ dari potensi lestarinya (Dinas Perikanan dan Kelautan Maluku, 2006).

Pukat cincin atau jaring giob adalah alat tangkap ikan pelagis dan merupakan alat tangkap alternatif di mana pada saat meningkatnya bahan bakar minyak kebanyakkan kapal long line, menurunkan waktu operasionalnya. Kapal pukat cincin termasuk ke dalam kelompok kapal yang mengoperasikan alat dengan cara melingkar gerombolan ikan (schooling fish). Untuk itu maka kapal pukat cincin dituntut memiliki stabilitas dan kemampuan olah gerak (manouverability) yang baik. Pada umumnya kapal pukat cincin memiliki badan kapal berbentuk $\mathrm{V}$ di bagian haluan, bentuk round sampai dengan $U$ pada bagian tengah kapal dan bentuk U di bagian buritan kapal (Pujiyati, 1995 dalam Rafni, 1999). Di Maluku Tengah, desain kapal-kapal pukat cincin standar umum tersebut disesuaikan dengan alat tangkap yang dipakai secara tradisional daerah setempat.

Produksi dari armada kapal penangkap selama beroperasi di laut berfluktuasi. Kondisi ini dipengaruhi oleh banyak faktor, di antaranya kecukupan bahan bakar minyak, cuaca yang selalu berubah-ubah dan sulit diprediksi, serta jarak lokasi penangkapan ikan (fishing ground) yang pada tahun-tahun belakangan ini semakin jauh. Dengan demikian, produktivitas yang rendah dari perikanan skala kecil juga pada umumnya diakibatkan oleh rendahnya keterampilan dan pengetahuan serta penggunaan alat maupun kemampuan jelajah armada dan teknologi penangkapan yang kurang memadai, sehingga efektivitas dan efisiensi penggunaan alat tangkap dan armada penangkapan belum optimal. Keadaan ini mempengaruhi tingkat penerimaan dan tingkat kesejahteraan masyarakat dibandingkan dengan penerimaan dari perikanan berskala besar (Barus et al., 1991).

Dilihat dari faktor sosial dan ekonomi, kegiatan perikanan skala kecil memerlukan penerapan manajemen perikanan yang lebih spesifik, karena keterampilan dan kemampuan aplikasi teknologi yang rendah. Seleksi teknologi menurut Haluan \& Nurani (1988) dalam Namsa (2006), dapat dilakukan melalui pengkajian aspek biotechnico-sosio-economic-approach. Terdapat 4 aspek yang dipenuhi oleh suatu jenis teknologi penangkapan ikan yang akan dikembangkan, yaitu 1) ditinjau dari biologi tidak merusak atau mengganggu kelestarian sumber daya; 2) secara teknis dapat efektif digunakan; 3) dari segi sosial dapat diterima masyarakat nelayan; 4) 
secara ekonomi teknologi tersebut bersifat menguntungkan, di samping adanya perizinan dari pemerintah sehingga tidak selalu terjadi IUUFishing. Tulisan ini mengatakan hasil kajian terhadap faktorfaktor produksi yang berpengaruh terhadap hasil tangkapan dan menetapkan strategi pengembangan usaha pukat cincin di perairan Maluku Tengah.

\section{BAHAN DAN METODE}

\section{Pengumpulan Data}

Penelitian dilakukan di perairan Laut Banda dan Pulau Ambon pada bulan Nopember 2005-April 2006. Data yang dikumpulkan untuk analisis adalah data primer dan sekunder. Data primer dikumpulkan melalui wawancara dengan pelaku atau nelayan dan pengusaha. Data sekunder di dapat langsung dari beberapa kantor yaitu kantor Dinas Perikanan dan Kelautan, Pelabuhan Perikanan Nusantara. Data yang dikumpulkan adalah ukuran kapal $\sum$ pukat cincin atau jaring giob, jumlah hasil i tangkapan, dan jenis ikan yang tertangkap. Data tentang jumlah armada kapal per pemilik, jumlah hari penangkapan, yang diduga mempengaruhi hasil atau pendapatan pemilik usaha perikanan pukat cincin, juga dikumpulkan. Data statistik produksi tangkapan diambil dari produksi tahun 2004-2005 (Dinas Perikanan dan kelautan Propinsi Maluku, 2005).

\section{Analisis Data}

Dalam penelitian ini dilakukan pendekatan studi bertahap. Tahap awal, mengidentifikasi faktor-faktor produksi, kemudian dianalisis dengan regresi linier berganda. Selanjutnya, menginventarisasi data investasi pukat cincin atau jaring giob yang optimal. Berdasarkan pada hasil inventarisasi data investasi tersebut, dianalisis kelayakan usaha sesuai output yang diinginkan dengan mengacu pada nilai kelayakkan usaha yang optimal. Faktor internal dan eksternal yang berpengaruh dalam perikanan pukat cincin dianalisis dengan SWOT.

\section{Analisis Fungsi Produksi}

Hubungan antara faktor-faktor produksi dengan produksi unit penangkapan pukat cincin dianalisis dengan statistik multi variabel menggunakan perangkat lunak Minitab (Mattjik \& Sumertajaya, 2000). Hubungan tersebut representasikan sebagai fungsi Cob Douglass (Panayotou, 1986; Khaled, 1986; Soekartawi, 1994) dengan tahapan sebagai berikut:

a. Menentukan terjadinya korelasi antar variabel. Apabila terjadi korelasi dari berbagai variabel yang dipilih dalam model regresi, angka yang tercantum dalam korelasi menunjukan sampai dengan seberapa besar (seberapa serius) hubungan antara setiap variabel $b_{i}$ Inter $x_{j}$ sebut. Bila secara statistik tidak ada korelasi yang kuat $(r \geq 0,8)$, maka 2 variabel tersebut perlu dipertimbangkan apakah diikutkan atau tidak dalam model.

b. Menghitung koefisien regresi berganda fungsi Cob Douglass, jika tidak terjadi interaksi, maka digunakan persamaan

in $Y=$

Tetapi jika ada interaksi persamaan yang digunakan adalah:

$$
\begin{aligned}
& \text { in } Y=\sum_{i}^{n} b_{i} \ln X_{i}+0,5 \sum_{i}^{n} \sum_{j}^{m} b i j \ln X_{i} \ln X_{j} \ldots(1 \\
& \text { di mana: } \\
& \mathrm{Y}=\text { hasil tangkapan } \\
& \Sigma=1,2,3,4,5 \text { : jumlah faktor } \\
& \text { produksi } \\
& b_{i}=(i=1,2,3, . ., n) \text { : koefisien }
\end{aligned}
$$




$$
\begin{aligned}
& \text { produksi } \\
&=(\mathrm{i}=1,2,3, \ldots ., \mathrm{n}): \text { koefisien } \\
& \text { produksi } \\
& \mathrm{Xi}=(\mathrm{i}=1,2,3, \ldots ., \mathrm{n}): \text { faktor } \\
& \text { produksi } \\
& \mathrm{Xj}=(\mathrm{i} \neq \mathrm{j}=1,2,3, \ldots \ldots, \mathrm{n}) \text { : faktor } \\
& \text { produksi } \\
& 0,5= \text { nilai dari hasil perkalian } 2 \text { variabel } \\
& \text { independen }(\mathrm{Xi} \text { dan } \mathrm{Xj}) \text { yang } \\
& \text { dijadikan variabel baru }
\end{aligned}
$$

Metode hipotetik fungsi produksi pukat cincin adalah:

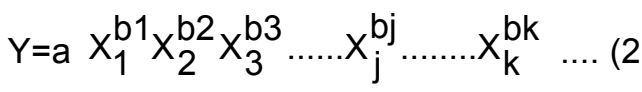

di mana:

$$
\begin{array}{lll}
Y_{1}= & \text { produksi } \\
X_{1}= & \text { anak buah kapal } \\
X_{2}= & \text { alat tangkap } \\
X_{3}= & \text { harga bahan bakar minyak } \\
X_{5}= & \text { ukuran kapal } \\
X_{6}= & \text { jenis ikan yang ditangkap }
\end{array}
$$

Pengujian statistik terhadap hubungan faktor-faktor produksi yang dicapai dalam persamaan regresi linier berganda fungsi Cob-Douglass dilakukan sebagi berikut:

a. Pengujian terhadap pengaruh faktorfaktor produksi $X_{1}$ secara bersama-sama terhadap produksi hasil tangkapan $(\mathrm{Y})$ dilakukan dengan uji $F$ dengan tujuan untuk melihat signifikansi dari faktorfaktor produksi terhadap produksi hasil tangkapan.

b. Pengaruh masing-masing faktor produksi terhadap produksi hasil tangkapan dilakukan dengan menguji apakah b (slope) tersebut berbeda atau sama dengan nol $(\mathrm{Ho}=0$ atau $\mathrm{Ho} \neq 0)$. Pengujian dilakukan dengan uji statistik t.

\section{Analisis SWOT}

Untuk menguji kelayakan usaha dalam perikanan pukat cincin ini, maka dilakukan analisis SWOT dengan mengidentifikasi berbagai faktor internal dan faktor eksternal. Faktor internal dianalisis berdasarkan pada kekuatan (strenghts) dan kelemahan (weakness), sedangkan faktor eksternal dianalisis berdasarkan pada peluang (oppertunities) dan ancaman (threats) (Salusu, 1996).

Analisis SWOT adalah identifikasi berbagai faktor secara sistematis untuk merumuskan strategis perusahaan. Analisis ini didasarkan pada logika yang dapat memaksimalkan kekuatan (strenghts) dan peluang (oppertunities), namun secara bersama dapat meminimalkan kelemahan (weakness) dan ancaman (threats). Proses pengambilan keputusan selalu berkaitan dengan pengembangan misi, tujuan, strategi, dan kebijakan perusahaan (Rjangkuti, 2004).

Salah satu model analisis SWOT dapat ditampilkan dalam bentuk matriks kotak, 2 yang sebelah kiri adalah kotak faktor eksternal peluang dan ancaman, sedangkan 2 kotak paling di atas adalah faktor internal, yaitu kekuatan dan kelemahan. Empat kotak lainnya merupakan kotak isu-isu strategis yang timbul sebagai hasil kontak antara faktorfaktor eksternal dan internal. Isu strategis tersebut adalah: A) comparative advantage, B) mobilization, C) investment, dan (D) damage control (Salusu, 1996 dalam Namsa, 2006). Model analisis yang mengacu pada Salusu (1996) (Tabel 1). 
Tabel 1. Matriks untuk analisis SWOT

Table 1. Matrix for SWOT analysis

\begin{tabular}{lll}
\hline \multicolumn{2}{c}{ Faktor internal } & \multicolumn{2}{c}{ Kekuatan/Strength } & \multicolumn{1}{c}{ Kelemahan/Weaknesses } \\
\hline Peluang/Opportunities & A. Comparative advantage & B. Mobilization \\
& Strategis SO & Strategis WO \\
Ancaman/Threats & C. Investment divestment & D. Damage Control \\
& Strategis ST & Strategis WT \\
\hline
\end{tabular}

Dari hasil identifikasi terhadap faktor eksternal dan internal tersebut, selanjutnya dibuat tabel matriks internal faktor evaluation yang memuat atau menetapkan bobot, rating dan nilai dari faktor-faktor kekuatan (strength $=S$ ) dan kelemahan (weakness = W) sebagai faktor internal. Faktor eksternal merupakan cakupan dari peluang (opportunity $=0$ ) dan ancaman (threats $=\mathrm{T}$ ) yang disebut matriks external factor evaluation.

\section{HASIL DAN BAHASAN}

\section{Perikanan}

\section{Sumber Daya Ikan}

Perairan Laut Banda dan Pulau Ambon Maluku Tengah memiliki luas secara keseluruhan $712,479.69 \mathrm{~km}$ yang terdiri atas luas laut 658,294 km (92,4\%) dan luas daratan 54,185 km (7,6\%). Potensi sumber daya perikanan di perairan ini diestimasi 1,640,160 ton per tahun (BRKP-P20 LIPI, 2001). Potensi tersebut terdiri atas ikan pelagis, demersal, dan biota laut lain yang perlu dieksploitasi secara optimal. Dari potensi yang tersedia pada tahun 2005 telah dimanfaatkan 481.847,8 ton.

Perairan Laut Banda, Ambon, dan sekitarnya mengalami 2 musim dalam setahun, yaitu musim timur (penghujan) terjadi dari bulan Mei-Oktober dan musim barat (kemarau), terjadi dari bulan Desember-Maret. Pada saat bertiup angin timur kebanyakkan nelayan ataupun pengusaha kapal pukat cincin jarang untuk melaut. Hal ini disebabkan karena gelombang yang cukup tinggi, mencapai 2$3 \mathrm{~m}$ dan pada umumnya cuaca berawan tebal, kecepatan arus rata-rata 1 knot. Suhu permukaan laut berkisar antara $26,5-27,5^{\circ} \mathrm{C}$ dan suhu udara antara $28,0-29^{\circ} \mathrm{C}$. Selanjutnya ketika musim barat tiba kegiatan penangkapan berjalan dengan baik, sejalan dengan membaiknya keadaan laut. Tinggi gelombang hanya berkisar antara 0,5-1 m, cuaca cerah, kecepatan arus rata-rata 0,55 knot, sementara suhu permukaan air laut berkisar antara $28-30^{\circ} \mathrm{C}$ pada suhu udara $30-33^{\circ} \mathrm{C}$.

\section{Armada Perikanan}

Untuk penangkapan ikan, para nelayan memiliki kapal atau armada perikanan sebagai transportasi untuk mencari daerah tangkapan (fishing ground) di perairan Laut Banda dan sekitarnya, yang mencakup perahu tanpa motor, motor temple, dan kapal bermotor (Gambar 1). 


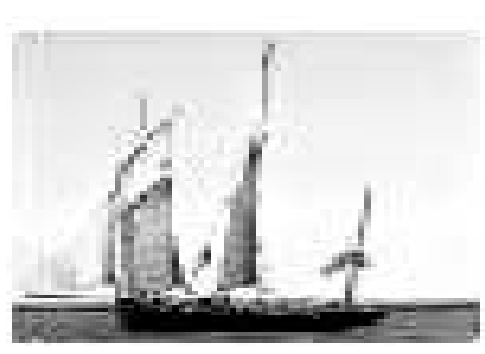

1

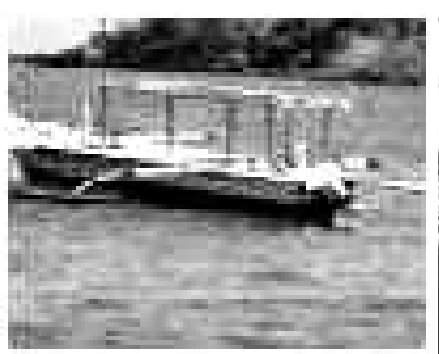

2

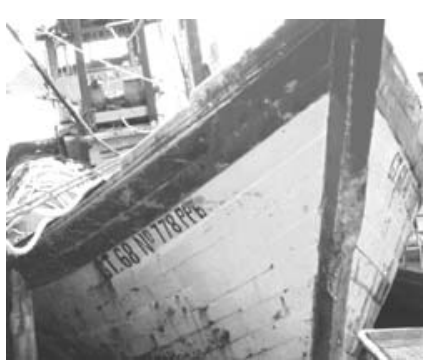

3

Gambar 1. Kapal penangkap ikan 1) perahu tanpa motor; 2) motor temple; 3) kapal motor.

Figure 1. Fishing boat 1) without engine; 2) outboard engine; 3) inboard engine.

\section{STRUKTUR ARM ADA PERIKANAN M ALUKU TENGAH}

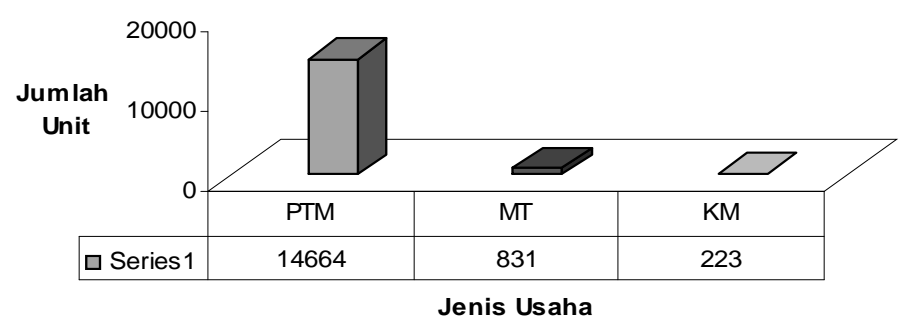

Gambar 2. Struktur armada perikanan di Maluku Tengah, pada tahun 2005.

Figure 2. S Structure of fishing fleet in Central Mollucas in 2005

Gambar 2 menunjukkan bahwa usaha perikanan tanpa motor lebih mendominansi daerah Maluku Tengah. Hal ini disebabkan nelayan tidak begitu saja dapat meninggalkan cara-cara konvensional dalam memperoleh hasil tangkapan di laut. Karena modal usaha yang minim dan harga bahan bakar minyak semakin tidak terjangkau, maka hanya sedikit nelayan menggunakan motor tempel atau kapal motor. Usaha perikanan yang menggunakan motor tempel dan kapal motor, yang jumlahnya tidak banyak, berbentuk kemitraan dengan pihak pengusaha bermodal.

Usaha pukat cincin di Maluku Tengah menurun pada tahun 2005 akibat konflik sosial yang terjadi. Sebagian besar kapalkapal pukat cincin di wilayah ini berpindah basis ke tempat yang lebih aman untuk menyelamatkan aset-aset mereka, seperti ke Papua, Manado, Ujung Pandang, dan Kendari. Padahal sebelum konflik terjadi, banyak pengusaha-pengusaha perikanan pukat cincin beroperasi di daerah Laut Banda dan Pulau Ambon.

Untuk menangkap ikan pelagis kecil dengan menggunakan pukat cincin di Laut Banda dan sekitarnya nelayan pada umumnya menggunakan kapal dengan ukuran 30-50 GT dengan mesin berkekuatan 120-300 HP bermerek Dompeng, Yanmar, Nissan, dan Mitsubishi dengan perlengkapan fish finder. Kapal 
pukat cincin ini terbuat dari bahan kayu, seperti meranti, damar laut, dan kayu rasak. Pada umumnya memiliki panjang 15$22 \mathrm{~m}$ dengan lebar 30-50 m kedalaman 2 m. Operasi penangkapan dilakukan malam hari. Untuk menarik ikan agar berkumpul menggunakan lampu halogen yang dipasang pada sisi kiri dan kanan kapal.
Pukat cincin merupakan salah satu alat tangkap yang banyak digunakan oleh para nelayan yang ada di Laut Banda dan Pulau Ambon, bersama-sama jenis alat tangkap lain seperti pukat tarik, pukat kantong, dan jaring insang (Gambar 3).

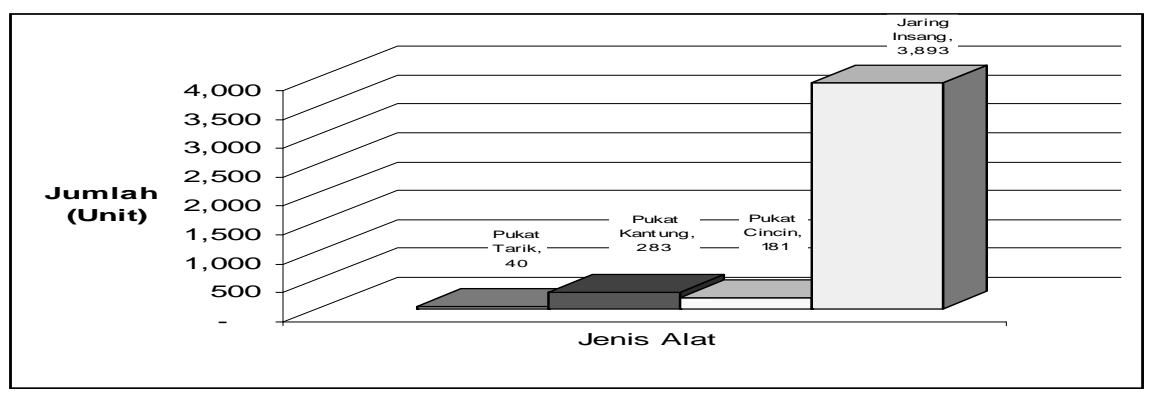

Gambar 3. Jumlah unit penangkapan menurut jenis alat tangkap di Maluku Tengah, tahun 2005.

Figure 3. Total fishing unit by gear type in Central Mollucas, 2005.

Jenis alat tangkap yang paling banyak dipakai oleh nelayan maupun pengusaha perikanan skala kecil adalah jaring insang, yang mencapai 3.893 unit. Pukat cincin sendiri hanya mencapai 181 buah pada tahun 2005. Dari sisi desain, alat tangkap dan metode penangkapan, pukat cincin yang dioperasikan oleh nelayan di daerah Laut Banda dan Pulau Ambon tidak jauh berbeda dengan yang ada di Jawa ataupun di Ternate. Pada Umumnya jaring pukat cincin memiliki panjang antara 500-1.000 $\mathrm{m}$ dan dalam (lebar) $50 \mathrm{~m}$.

\section{Nelayan}

Nelayan merupakan aset yang terpenting dalam pengoperasian alat tangkap pukat cincin (purse seine). Pada tahun 2004 tercatat 33.485 nelayan, mengalami peningkatan pada tahun 2005 yaitu 13,5\% (38.052). Secara keseluruhan, kenaikan yang terjadi pada perikanan tangkap di laut 37.562 (13,7\%) (Dinas Perikanan dan kelautan Propinsi Maluku, 2005).

Usaha perikanan pukat cincin, selain jenis alat tangkap lain, di daerah Maluku Tengah mulai bangkit kembali pasca konflik sosial karena prospek yang paling berpotensi adalah di laut. Setiap unit armada pukat cincin memiliki jumlah anak buah kapal yang berbeda-beda tergantung ukuran kapal yang digunakan. Untuk motor tempel (outboard) diperlukan 5 orang, sedangkan untuk kapal dengan bobot di atas 100 GT menggunakan anak buah kapal lebih banyak, dapat mencapai 23 orang dengan tugas masing-masing dikapal. Komposisi pembagian tugas pada kapal pukat cincin dan bagi hasil (Tabel 2). 
Tabel 2. Pembagian tugas dan sistem bagi hasil pada perikanan pukat cincin di Ambon

Table 2. Job description and profit sharing system of the crews of purse seine fishery in Ambon

\begin{tabular}{|c|c|c|c|c|c|}
\hline \multirow{2}{*}{ No. } & \multirow{2}{*}{ Perincian tugas } & \multirow{2}{*}{ Jumlah orang } & \multicolumn{2}{|c|}{ Pembagian pendapatan } & \multirow{2}{*}{$\begin{array}{c}40 \% \text { dari } \\
\text { Keuntungan }\end{array}$} \\
\hline & & & Bagian $A B K$ & Jumlah bagian & \\
\hline 1. & Juragan & 1 & 2 & 2 & 5,00 \\
\hline 2. & Juru mesin & 1 & 2 & 2 & 5,00 \\
\hline 3. & Juru pelampung & 3 & 1 & 3 & 4,50 \\
\hline 4. & Juru pemberat & 3 & 1 & 3 & 5,50 \\
\hline 5. & Juru jaring & 10 & 1 & 10 & 25,00 \\
\hline 6. & Juru pantau & 1 & 1 & 1 & 3,00 \\
\hline 7. & Juru tali kolor & 4 & 2 & 4 & 2,00 \\
\hline & Jumlah & 23 & 10 & 25 & 50,00 \\
\hline
\end{tabular}

Ikan hasil tangkapan dijual di tempat pendaratan ikan. Sistem pembagian keuntungan yang dilakukan antara pemilik modal dengan anak buah kapal adalah $60: 40$.

\section{Faktor Produksi}

Faktor-faktor produksi yang diduga mempengaruhi produksi pukat cincin adalah anak buah kapal, ukuran alat tangkap, bahan bakar minyak per tahun, dan ukuran kapal (GT), sedangkan jumlah produksi tangkapan ikan pelagis kecil dan besar digunakan sebagai indikator (variabel dependent). Gambar 4 menjelaskan faktorfaktor produksi yang berpengaruh terhadap jumlah produksi.

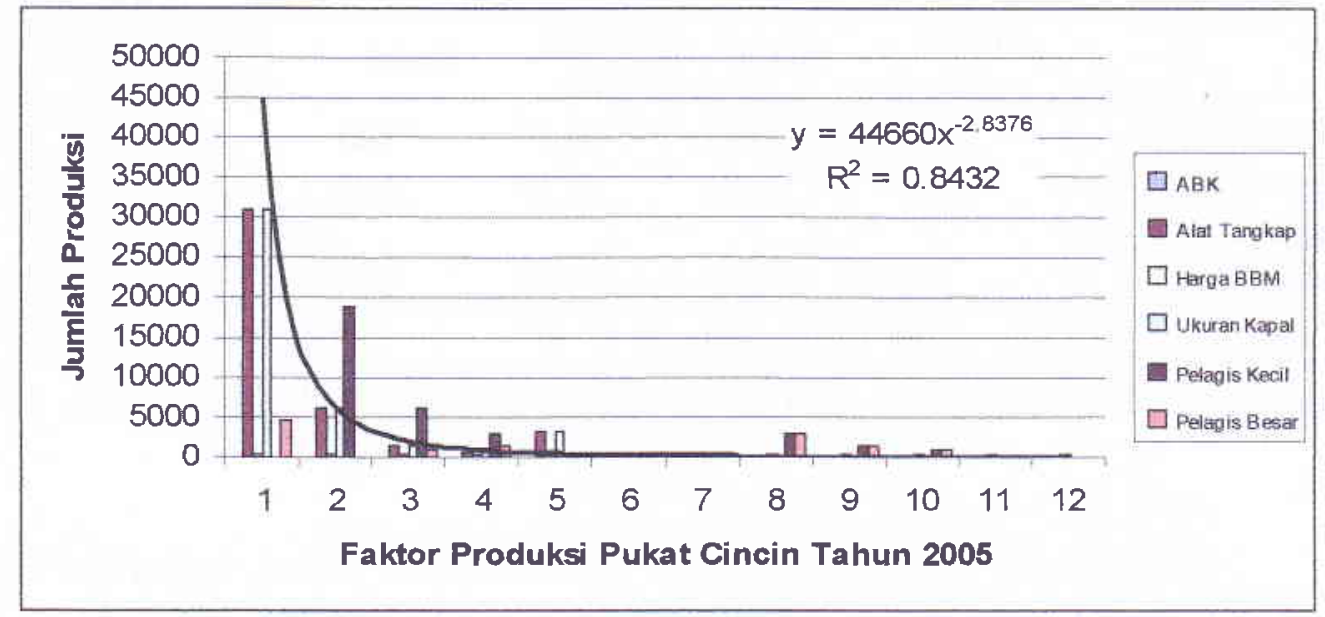

Gambar 4. Hubungan antara faktor-faktor produksi pukat cincin dengan jumlah produksi.

Figure 4. Relationship between purse seine production factors and production 
Dari Gambar 4 dapat dilihat bahwa dalam bulan Januari tahun 2005, terjadi peningkatan kegiatan melaut yang kemudian mengalami penurunan pada bulan Pebruari, namun hasil tangkapan yang menonjol hanya pada kelompok ikan pelagis besar. Untuk tangkapan ikan pelagis kecil, terlihat meningkat setelah bulan Pebruari, namun menurun mulai bulan Mei. Hal ini disebabkan terjadinya pergantian musim di mana sebagian besar nelayan tidak melaut. Di bulan Agustus penangkapan ikan pelagis

Tabel 3.

Analisis variance ANOVA Table 3. kecil maupun besar hanya dilakukan oleh armada perahu tanpa motor. Hasil penelitian menunjukkan harga bahan bakar minyak yang menjadi kendala.

Hasil analisis dengan uji $F$ hitung (ANOVA), menunjukkan nilai $F=3,75$ sedangkan nilai $P=0,069$. Dengan demikian, semua variabel independen berpengaruh signifikan terhadap produksi hasil tangkapan (variabel dipenden) pada tingkat kepercayaan 95\% (Tabel. 3).

\begin{tabular}{lccccc}
\hline \multicolumn{1}{c}{ Sumber } & $\mathbf{d b}$ & $\mathbf{J k}$ & $\mathbf{K t}$ & $\mathbf{F}$ & $\mathbf{P}$ \\
\hline Regresi & 5 & $2.19995 \mathrm{E}+14$ & $4.39991 \mathrm{E}+13$ & 3,75 & 0,069 \\
Galat & 6 & $7.04808 \mathrm{E}+13$ & $1.17468 \mathrm{E}+13$ & & \\
\hline Total & $\mathbf{1 1}$ & $\mathbf{2 . 9 0 4 7 6 E + 1 4}$ & & \\
\hline
\end{tabular}

Untuk pengoperasian pukat cincin, selain faktor harga bahan bakar minyak, diperlukan nelayan yang berkemampuan dan memiliki keterampilan khusus. Hasil analisis mengunakan ANOVA tersebut secara implisit menyarankan bahwa untuk mendapatkan hasil tangkapan yang tinggi ditunjang oleh kapal, ukuran alat tangkap, bahan bakar minyak dan keterampilan dari anak buah kapal yang sesuai dan memadai.

\section{Keterkaitan Faktor-Faktor Usaha}

Untuk melihat peluang dalam perikanan pukat cincin di Maluku Tengah dan meminimalkan kelemahan dan ancaman, maka kajian dilakukan menggunakan analisis SWOT. Langkah awal dalam analisis SWOT ini adalah mengidentifikasi faktor-faktor internal dan eksternal yang mempengaruhi usaha perikanan pukat cincin.

Nelayan di Maluku Tengah memiliki keterampilan melaut dan aktivitas penangkapan yang cukup tinggi, perairan yang luas, dan potensi perikanan laut yang tinggi. Faktor-faktor tersebut merupakan kekuatan. Sementara faktor-faktor lain yang merupakan kelemahan adalah faktor konflik sosial, ketersediaan bahan bakar minyak, pengetahuan, dan keterampilan teknis operasional pukat cincin, sarana tempat pendaratan ikan, dan sistem penjualan hasil tangkapan.

\section{Faktor Internal}

Faktor internal yang diperhitungkan sebagai kekuatan adalah tingkat kemampuan pemahaman dan penguasaan teknologi yang dimiliki, potensi produksi, dan jumlah armada. Faktor internal yang merupakan kelemahan yang diperhitungkan adalah sarana tempat pendaratan ikan, konflik sosial, dan tingkat pendidikan.

\section{Faktor Eksternal}

Peluang yang menjadi faktor eksternal dalam usaha perikanan pukat cincin di Maluku Tengah adalah peluang investor menanamkan modal, sedangkan faktorfaktor eksternal yang diperhitungkan 
sebagai ancaman adalah fluktuasi harga ikan, harga bahan bakar minyak, dan kompetisi jual-beli yang tidak sehat.

\section{Implikasi Kebijakan Usaha Pukat Cincin}

Berdasarkan pada faktor-faktor internal dan eksternal, maka dari analisis SWOT di dapat 5 variabel yang diperhitungkan dalam mengembangkan perikanan pukat cincin di Maluku Tengah, yaitu 1) industri pengolahan produk perikanan (strategi S-O); 2) manfaat tempat pendaratan ikan (strategi W-O); 3) diversifikasi usaha produk olahan perikanan (strategi W-O); 4) cold storage (strategi ST); dan 5) pendirian solar packet dealer for fishermen (strategi $W$-T). Variabel-variabel tersebut disusun dalam matriks (Tabel 4).

Tabel 4. Matriks analisis SWOT

Table 4. SWOT Matrix Analysis

\begin{tabular}{|c|c|c|}
\hline \multirow{3}{*}{ Faktor internal } & Kekuatan/Strength & Kelemahan/Weaknesses \\
\hline & 1. Penguasan teknologi pukat cincin & 1. Sarana TPI \\
\hline & 2. Produksi perikanan & 2. Konflik sosial \\
\hline Faktor eksternal & 3. Jumlah armada & 3. Tingkat pendidikan \\
\hline Peluang/Oppertunity & Srategi S-O & Strategi W-O \\
\hline \multirow[t]{2}{*}{ 1. Investor menanam modal } & - Industri pengolahan hasil & - Manfaat TPI (W1, W2, 01, 02) \\
\hline & perikanan $(\mathrm{S} 2, \mathrm{O} 2)$ & - Diversifikasi perikanan $(W 3,01)$ \\
\hline Ancaman/Threats & Strategi S-T & Strategi W-T \\
\hline 1. Fluktuasi harga ikan & - Cold storage (S2, T1, T3) & - Pendirian solar packed \\
\hline 2. Harga BBM & & dealer for fishermen (W2, T2) \\
\hline 3. Kompetisi yang tidak sehat & & dan kondisi keamanan \\
\hline
\end{tabular}

\section{Matriks Internal Factor Evaluation}

Matriks internal factor evaluation merupakan cakupan dari kekuatan (strengths $=S$ ) dan kelemahan (weakness
$=W$. Penetapan nilai didasarkan pada prioritas strategi melalui pembobotan terhadap faktor-faktor dalam matriks internal factor evaluation (Tabel 5).

Tabel 5.

Hasil analisis terhadap faktor-faktor internal dalam matriks internal factor evaluation

Table 5. Results of the analysis of internal factors in internal factor evaluation matrix

\begin{tabular}{clccc} 
No. & \multicolumn{1}{c}{ Faktor Internal } & Bobot & Rating & Nilai \\
\hline & Kekuatan/Strength & & & \\
1. & Penguasaan teknologi pukat cincin & 0,20 & 4 & 0,80 \\
2. Produksi perikanan & 0,30 & 4 & 0,80 \\
3. Jumlah armada & 0,20 & 3 & 0,50 \\
& Kelemahan/Weakness & & & \\
1. Sarana TPI & 0,25 & 3 & 0,50 \\
2. Konflik sosial & 0,30 & 3 & 0,80 \\
3. Tingkat pendidikan & 0,15 & 1 & 0,20 \\
\hline
\end{tabular}

Keterangan: rating 1 = sangat lemah; 2 = agak lemah; 3 = agak kuat; 4 = sangat kuat 
Kajian Usaha Pukat Cincin.... Pendaratan di Maluku Tengah (Mahulette, R. T. \& Wijopriono)

\section{Matriks External Factor Evaluation}

Matriks external factor evaluation merupakan cakupan dari peluang (opportunity $=0$ ) dan ancaman (threats =
T). Penetapan nilai didasarkan pada prioritas strategi melalui pembobotan terhadap faktor-faktor dalam matriks internal factor evaluation (Tabel 6).

Tabel 6.

Hasil analisis terhadap faktor-faktor internal dalam matriks external factor evaluation

Table 6. Results of the analysis of external factors in external factor evaluation matrix

\begin{tabular}{clccc}
\hline No. & \multicolumn{1}{c}{ Faktor eksternal } & Bobot & Rating & Nilai \\
\hline & Peluang/Opportunity & & & \\
1. & Investor menanam modal & 0,30 & 4 & 1,20 \\
Ancaman/Threats & & & \\
1. Fluktuasi harga ikan & 0,10 & 3 & 0,30 \\
2. Harga BBM & 0,50 & 4 & 1,00 \\
3. Kompetisi yang tidak sehat & 0,20 & 2 & 0,70 \\
\hline & $\mathbf{1 , 1 0}$ & & $\mathbf{3 , 2 0}$ \\
\hline
\end{tabular}

Keterangan: rating $1=$ sangat lemah; 2 = agak lemah; $3=$ agak kuat; $4=$ sangat kuat

3. Matriks Quantitative Strategic Planing management

Matriks quantitative strategic planing management merupakan analisis lebih lanjut untuk strategi alternatif terbaik.
Analisis ini adalah pola pengelompokan berdasarkan pada asumsi, yang mana lebih diterima. Hasil analisis dengan matrik quantitative strategic planing management (Tabel 7).

Tabel 7.

Hasil analisis matriks quantitative strategic planing management Table 7. Results of quantitative strategic planing management Matrix Analysis

\begin{tabular}{|c|c|c|c|c|c|c|c|c|c|c|c|}
\hline \multirow{3}{*}{ Faktor kunci } & \multirow{3}{*}{$\begin{array}{c}\text { Nilai } \\
\text { Rata-rata }\end{array}$} & \multicolumn{10}{|c|}{ Strategi alternatif } \\
\hline & & \multicolumn{2}{|c|}{ Strategi 1} & \multicolumn{2}{|c|}{ Strategi 2} & \multicolumn{2}{|c|}{ Stratei 3} & \multicolumn{2}{|c|}{ Strategi 4} & \multicolumn{2}{|c|}{ Strategi 5} \\
\hline & & AS & WAS & AS & WAS & AS & WAS & AS & WAS & AS & WAS \\
\hline Kekuatan 1 & 0,20 & 4 & 1,00 & 4 & 1,00 & 4 & 1,00 & 4 & 1,00 & 3 & 0,80 \\
\hline Kekuatan 2 & 0,30 & 4 & 1,00 & 4 & 1,00 & 4 & 1,00 & 3 & 0,75 & 4 & 1,00 \\
\hline Kekuatan 3 & 0,20 & 3 & 0,60 & 3 & 0,60 & 3 & 0,75 & 2 & 0,80 & 3 & 0,60 \\
\hline Kelemahan 1 & 0,20 & 3 & 0,75 & 3 & 0,60 & 3 & 0,60 & 4 & 1,00 & 4 & 1,00 \\
\hline Kelemahan 2 & 0,25 & 3 & 0,60 & 3 & 0,75 & 3 & 0,50 & 3 & 0,75 & 3 & 0,60 \\
\hline Peluang & 0,30 & 4 & 1,00 & 4 & 1,00 & 4 & 1,00 & 4 & 1,00 & 3 & 0,75 \\
\hline Ancaman 1 & 0,10 & 3 & 0,60 & 3 & 0,60 & 4 & 1,00 & 3 & 0,50 & 3 & 0,60 \\
\hline Ancaman 2 & 0,50 & 4 & 1,00 & 3 & 0,75 & 2 & 0,20 & 3 & 0,60 & 2 & 0,25 \\
\hline Ancaman 3 & 0,20 & 2 & 0,25 & 2 & 0,25 & 2 & 0,25 & 2 & 0,75 & 2 & 0,20 \\
\hline Total & & & 6,8 & & 6,55 & & 6,3 & & 7,15 & & 5,8 \\
\hline
\end{tabular}

Hasil analisis menunjukkan bahwa tingkat kemampuan pemahaman teknologi yang dimiliki oleh nelayan di Maluku Tengah cukup tinggi (Tabel 6), sehingga keterampilan dalam mengoperasikan pukat cincin meningkat dari tahun ke tahun. Potensi perikanan pelagis kecil dan besar didapati sangat besar, sementara dilihat dari 
jumlah spesies ikan yang tertangkap, didapati sangat beragam. Jumlah armada cukup banyak, termasuk kapal yang dioperasikan tanpa motor. Faktor-faktor internal ini merupakan kekuatan dalam mengembangkan alat tangkap pukat cincin.

Faktor internal yang merupakan kelemahan dalam perikanan pukat cincin adalah permainan harga jual. Terkadang produksi yang tertangkap dijual langsung di laut atau diijonkan kepada para tengkulak. Selain itu, fungsi tempat pendaratan ikan tidak lagi sebagaimana dan terjadinya konflik sosial yang membuat kegiatan penangkapan terganggu, terutama bagi para pengusaha. Selain itu, tingkat pendidikan anak buah kapal yang rendah membuat penguasaan teknologi pukat cincin menjadi rendah.

Peluang yang menjadi faktor eksternal dalam usaha perikanan pukat cincin di Maluku Tengah adalah terbukanya kesempatan untuk para investor untuk menanamkan modal karena potensi luasan daerah laut yang sangat besar. Potensi luasan laut menjadi suatu daya dukung yang kuat dalam mengekspor hasil perikanan ke luar negeri. Harga bahan bakar minyak yang tinggi menyebabkan pengeluaran biaya yang besar dalam operasi penangkapan ikan. Kompetisi yang tidak sehat dalam membeli dan menjual, terkadang sampai dengan terjadi ancaman bagi para pelaku usaha perikanan pukat cincin dari segi keamanan, membuat harga tidak selalu stabil.

Untuk meminimalkan kelemahankelemahan yang ada seperti disebutkan di atas yang nantinya akan mengancam kegiatan perikanan tangkap pukat cincin, yang mempunyai prospek ke depan cukup bagus, maka dimunculkan strategi untuk meningkatkan pemanfaatan sumber daya ikan. Berdasarkan pada urutan nilai-nilai yang diperoleh dalam analisis, strategi alternatif berdasarkan pada prioritas dalam pengembangan usaha perikanan pukat cincin berturut-turut adalah:

1. Diversifikasi produk pengolahan perikanan (nilai hasil analisis, 7,15).

2. Adanya industri pengolahan perikanan (nilai hasil analisis, 6,8).

3. Tersedianya cold storage (nilai hasil analisis, 6,55).

4. Manfaat tempat pendaratan ikan, (nilai hasil analisis, 6,3).

5. Keberadaan solar packed dealer for fishermen) (nilai hasil analisis, 5,8).

\section{KESIMPULAN DAN SARAN}

\section{Kesimpulan}

1. Laut Banda dan PulauAmbon berpotensi menghasilkan sumber daya yang sangat besar. Hasil tangkapan yang telah dicapai 444,5 ton per bulan untuk ikan pelagis kecil dan 183,2 ton per bulan untuk ikan pelagis besar adalah baru merupakan $59 \%$ dari potensi lestarinya. Dengan demikian, usaha perikanan pukat cincin sangat terbuka untuk dikembangkan.

2. Usaha perikanan pukat cincin di Maluku Tengah dipengaruhi oleh faktor-faktor internal dan ekternal. Hasil analisis menunjukkan bahwa faktor keterampilan dan kegiatan penangkapan memperoleh nilai (score) yang cukup tinggi, dan hal ini merupakan kekuatan. Sementara kelemahan yang mengganggu usaha adalah sering terjadinya konflik, kelangkaan bahan bakar minyak, rendahnya pengetahuan, dan keterampilan teknis operasional. Harga bahan bakar minyak yang yang tidak pernah turun, bahkan makin meningkat menyebabkan pengeluaran biaya operasional yang besar. 
3. Matriks external factor evaluation merupakan cakupan dari peluang (opportunity $=0$ ) dan ancaman (threats $=\mathrm{T}$ ). Pembobotan terhadap faktor-faktor (peluang dan ancaman) yang dianalisis dalam matriks external factor evaluation menunjukkan bahwa faktor peluang investor menanamkan modal dan harga bahan bakar minyak mendapatkan nilai 4 (sangat kuat). Strategi alternatif dalam sistem usaha perikanan pukat cincin di perairan Laut Banda dan Pulau Ambon adalah diversifikasi produk pengolahan perikanan, yang dalam analisis memperoleh nilai 7,15 (tertinggi).

\section{Saran}

Diharapkan perhatian dari lembaga pemerintahan dan instansi-instani terkait melihat ini sebagai peluang kebangkitan Maluku dari keterpurukkan. Perlu dibuat suatu kelembagaan yang dapat memperkuat hubungan dan kerja sama antara Pemerintah Daerah dengan Dinas Perikanan dan Kelautan setempat dengan Pusat Pelabuhan Nusantara, dalam mengatur serta mengelola situasi dan kondisi di Maluku agar tercipta kepastian hukum sehingga tercipta situasi usaha yang kondusif.

\section{DAFTAR PUSTAKA}

Barus, H. R., Badruddin, \& Naamin N. 1991. Prosiding Forum II Perikanan. Sukabumi 18-21 Juni 1991. Jakarta. Departemen Pertanian. Badan Penelitian dan Pengembangan Pertanian. Pusat Penelitian dan Pengembangan Perikanan. 91-105 $p$.

Badan Riset Kelautan dan PerikananLembaga Ilmu Pengetahuan Indonesia. 2001. Kerja Sama Badan Riset Kelautan dan Perikanan dan Pusat Penelitian dan
Pengembangan Oceanologi Lembaga IImu-Lembaga IImu Pengetahuan Indonesia.

Dinas Perikanan dan Kelautan Propinsi Maluku. 2005. Laporan Tahunan Statistik Perikanan Tahun 2004. Ambon.

Dinas Perikanan dan Kelautan Propinsi Maluku. 2006. Laporan Tahunan Statistik Perikanan Tahun 2005 Ambon.

Namsa, D. 2006. Analisis Pengembangan Perikanan Soma Pajeko (mini purse seine) di Perairan Tidore. Tesis.

Khaled, M. S. 1986. Production Technologi of the Riverine Fisheries in Bangladesh dalam Small-Scale Fisheries in Asia: Sosioeconomic Analysis And Policy. p. 113-120.

Latumeten, J. 1984. Perikanan bubu di daerah Latuhalat Kodya Ambon Provinsi Maluku. Skripsi.

Mattjik, A. A. \& Sumertajaya. 2000. Perancangan Percobaan dengan Aplikasi SAS dan Minitab. Jilid I. Institut Pertanian Bogor. Press. Bogor. 326 p.

Panayotou, T. 1986. Small Scale Fisheries in Asia. Sosio Economic Analysis and Policy. $283 \mathrm{p}$.

Rafni, Y. N. 1999. Studi Stimulasi Gerakkan Vertikal Kapal Purse Seine terhadap Gelombang Reguler Following Seas.

Rangkuti, F. 2004. Analisis SWOT teknik membedah kasus bisnis. Reorientasi Konsep Perencanaan Strategis untuk Menghadapi Abad 21. Penerbit PT. Gramedia Pustaka Utama. Jakarta. 188 p. 
J. Kebijak. Perikan. Ind. Vol.2 No.1 Mei 2010: 57 - 70

Soekartawi, N. S. 1994. Teori Ekonomi Produksi dengan Pokok Bahasan Analisis Fungsi Cob-Douglass. PT. Raja Grafindo Persada. 257 p.
Salusu, J. 1996. Pengambilan Keputusan Strategi untuk Organisasi Publik dan Organisasi Non Profit. Penerbit PT. Grasindo. Jakarta. 358 p. 
sebagai ancaman adalah fluktuasi harga ikan, harga bahan bakar minyak, dan kompetisi jual-beli yang tidak sehat.

\section{Implikasi Kebijakan Usaha Pukat Cincin}

Berdasarkan pada faktor-faktor internal dan eksternal, maka dari analisis SWOT di dapat 5 variabel yang diperhitungkan dalam mengembangkan perikanan pukat cincin di Maluku Tengah, yaitu 1) industri pengolahan produk perikanan (strategi S-O); 2) manfaat tempat pendaratan ikan (strategi W-O); 3) diversifikasi usaha produk olahan perikanan (strategi W-O); 4) cold storage (strategi ST); dan 5) pendirian solar packet dealer for fishermen (strategi $W$-T). Variabel-variabel tersebut disusun dalam matriks (Tabel 4).

Tabel 4. Matriks analisis SWOT

Table 4. SWOT Matrix Analysis

\begin{tabular}{|c|c|c|}
\hline \multirow{3}{*}{ Faktor internal } & Kekuatan/Strength & Kelemahan/Weaknesses \\
\hline & 1. Penguasan teknologi pukat cincin & 1. Sarana TPI \\
\hline & 2. Produksi perikanan & 2. Konflik sosial \\
\hline Faktor eksternal & 3. Jumlah armada & 3. Tingkat pendidikan \\
\hline Peluang/Oppertunity & Srategi S-O & Strategi W-O \\
\hline \multirow[t]{2}{*}{ 1. Investor menanam modal } & - Industri pengolahan hasil & - Manfaat TPI (W1, W2, 01, 02) \\
\hline & perikanan $(\mathrm{S} 2, \mathrm{O} 2)$ & - Diversifikasi perikanan $(W 3,01)$ \\
\hline Ancaman/Threats & Strategi S-T & Strategi W-T \\
\hline 1. Fluktuasi harga ikan & - Cold storage (S2, T1, T3) & - Pendirian solar packed \\
\hline 2. Harga BBM & & dealer for fishermen (W2, T2) \\
\hline 3. Kompetisi yang tidak sehat & & dan kondisi keamanan \\
\hline
\end{tabular}

\section{Matriks Internal Factor Evaluation}

Matriks internal factor evaluation merupakan cakupan dari kekuatan (strengths $=S$ ) dan kelemahan (weakness
$=W$. Penetapan nilai didasarkan pada prioritas strategi melalui pembobotan terhadap faktor-faktor dalam matriks internal factor evaluation (Tabel 5).

Tabel 5.

Hasil analisis terhadap faktor-faktor internal dalam matriks internal factor evaluation

Table 5. Results of the analysis of internal factors in internal factor evaluation matrix

\begin{tabular}{clccc} 
No. & \multicolumn{1}{c}{ Faktor Internal } & Bobot & Rating & Nilai \\
\hline & Kekuatan/Strength & & & \\
1. & Penguasaan teknologi pukat cincin & 0,20 & 4 & 0,80 \\
2. Produksi perikanan & 0,30 & 4 & 0,80 \\
3. Jumlah armada & 0,20 & 3 & 0,50 \\
& Kelemahan/Weakness & & & \\
1. Sarana TPI & 0,25 & 3 & 0,50 \\
2. Konflik sosial & 0,30 & 3 & 0,80 \\
3. Tingkat pendidikan & 0,15 & 1 & 0,20 \\
\hline
\end{tabular}

Keterangan: rating 1 = sangat lemah; 2 = agak lemah; 3 = agak kuat; 4 = sangat kuat 
Kajian Usaha Pukat Cincin.... Pendaratan di Maluku Tengah (Mahulette, R. T. \& Wijopriono)

\section{Matriks External Factor Evaluation}

Matriks external factor evaluation merupakan cakupan dari peluang (opportunity $=0$ ) dan ancaman (threats =
T). Penetapan nilai didasarkan pada prioritas strategi melalui pembobotan terhadap faktor-faktor dalam matriks internal factor evaluation (Tabel 6).

Tabel 6.

Hasil analisis terhadap faktor-faktor internal dalam matriks external factor evaluation

Table 6. Results of the analysis of external factors in external factor evaluation matrix

\begin{tabular}{clccc}
\hline No. & \multicolumn{1}{c}{ Faktor eksternal } & Bobot & Rating & Nilai \\
\hline & Peluang/Opportunity & & & \\
1. & Investor menanam modal & 0,30 & 4 & 1,20 \\
Ancaman/Threats & & & \\
1. Fluktuasi harga ikan & 0,10 & 3 & 0,30 \\
2. Harga BBM & 0,50 & 4 & 1,00 \\
3. Kompetisi yang tidak sehat & 0,20 & 2 & 0,70 \\
\hline & $\mathbf{1 , 1 0}$ & & $\mathbf{3 , 2 0}$ \\
\hline
\end{tabular}

Keterangan: rating $1=$ sangat lemah; 2 = agak lemah; $3=$ agak kuat; $4=$ sangat kuat

3. Matriks Quantitative Strategic Planing management

Matriks quantitative strategic planing management merupakan analisis lebih lanjut untuk strategi alternatif terbaik.
Analisis ini adalah pola pengelompokan berdasarkan pada asumsi, yang mana lebih diterima. Hasil analisis dengan matrik quantitative strategic planing management (Tabel 7).

Tabel 7.

Hasil analisis matriks quantitative strategic planing management Table 7. Results of quantitative strategic planing management Matrix Analysis

\begin{tabular}{|c|c|c|c|c|c|c|c|c|c|c|c|}
\hline \multirow{3}{*}{ Faktor kunci } & \multirow{3}{*}{$\begin{array}{c}\text { Nilai } \\
\text { Rata-rata }\end{array}$} & \multicolumn{10}{|c|}{ Strategi alternatif } \\
\hline & & \multicolumn{2}{|c|}{ Strategi 1} & \multicolumn{2}{|c|}{ Strategi 2} & \multicolumn{2}{|c|}{ Stratei 3} & \multicolumn{2}{|c|}{ Strategi 4} & \multicolumn{2}{|c|}{ Strategi 5} \\
\hline & & AS & WAS & AS & WAS & AS & WAS & AS & WAS & AS & WAS \\
\hline Kekuatan 1 & 0,20 & 4 & 1,00 & 4 & 1,00 & 4 & 1,00 & 4 & 1,00 & 3 & 0,80 \\
\hline Kekuatan 2 & 0,30 & 4 & 1,00 & 4 & 1,00 & 4 & 1,00 & 3 & 0,75 & 4 & 1,00 \\
\hline Kekuatan 3 & 0,20 & 3 & 0,60 & 3 & 0,60 & 3 & 0,75 & 2 & 0,80 & 3 & 0,60 \\
\hline Kelemahan 1 & 0,20 & 3 & 0,75 & 3 & 0,60 & 3 & 0,60 & 4 & 1,00 & 4 & 1,00 \\
\hline Kelemahan 2 & 0,25 & 3 & 0,60 & 3 & 0,75 & 3 & 0,50 & 3 & 0,75 & 3 & 0,60 \\
\hline Peluang & 0,30 & 4 & 1,00 & 4 & 1,00 & 4 & 1,00 & 4 & 1,00 & 3 & 0,75 \\
\hline Ancaman 1 & 0,10 & 3 & 0,60 & 3 & 0,60 & 4 & 1,00 & 3 & 0,50 & 3 & 0,60 \\
\hline Ancaman 2 & 0,50 & 4 & 1,00 & 3 & 0,75 & 2 & 0,20 & 3 & 0,60 & 2 & 0,25 \\
\hline Ancaman 3 & 0,20 & 2 & 0,25 & 2 & 0,25 & 2 & 0,25 & 2 & 0,75 & 2 & 0,20 \\
\hline Total & & & 6,8 & & 6,55 & & 6,3 & & 7,15 & & 5,8 \\
\hline
\end{tabular}

Hasil analisis menunjukkan bahwa tingkat kemampuan pemahaman teknologi yang dimiliki oleh nelayan di Maluku Tengah cukup tinggi (Tabel 6), sehingga keterampilan dalam mengoperasikan pukat cincin meningkat dari tahun ke tahun. Potensi perikanan pelagis kecil dan besar didapati sangat besar, sementara dilihat dari 
jumlah spesies ikan yang tertangkap, didapati sangat beragam. Jumlah armada cukup banyak, termasuk kapal yang dioperasikan tanpa motor. Faktor-faktor internal ini merupakan kekuatan dalam mengembangkan alat tangkap pukat cincin.

Faktor internal yang merupakan kelemahan dalam perikanan pukat cincin adalah permainan harga jual. Terkadang produksi yang tertangkap dijual langsung di laut atau diijonkan kepada para tengkulak. Selain itu, fungsi tempat pendaratan ikan tidak lagi sebagaimana dan terjadinya konflik sosial yang membuat kegiatan penangkapan terganggu, terutama bagi para pengusaha. Selain itu, tingkat pendidikan anak buah kapal yang rendah membuat penguasaan teknologi pukat cincin menjadi rendah.

Peluang yang menjadi faktor eksternal dalam usaha perikanan pukat cincin di Maluku Tengah adalah terbukanya kesempatan untuk para investor untuk menanamkan modal karena potensi luasan daerah laut yang sangat besar. Potensi luasan laut menjadi suatu daya dukung yang kuat dalam mengekspor hasil perikanan ke luar negeri. Harga bahan bakar minyak yang tinggi menyebabkan pengeluaran biaya yang besar dalam operasi penangkapan ikan. Kompetisi yang tidak sehat dalam membeli dan menjual, terkadang sampai dengan terjadi ancaman bagi para pelaku usaha perikanan pukat cincin dari segi keamanan, membuat harga tidak selalu stabil.

Untuk meminimalkan kelemahankelemahan yang ada seperti disebutkan di atas yang nantinya akan mengancam kegiatan perikanan tangkap pukat cincin, yang mempunyai prospek ke depan cukup bagus, maka dimunculkan strategi untuk meningkatkan pemanfaatan sumber daya ikan. Berdasarkan pada urutan nilai-nilai yang diperoleh dalam analisis, strategi alternatif berdasarkan pada prioritas dalam pengembangan usaha perikanan pukat cincin berturut-turut adalah:

1. Diversifikasi produk pengolahan perikanan (nilai hasil analisis, 7,15).

2. Adanya industri pengolahan perikanan (nilai hasil analisis, 6,8).

3. Tersedianya cold storage (nilai hasil analisis, 6,55).

4. Manfaat tempat pendaratan ikan, (nilai hasil analisis, 6,3).

5. Keberadaan solar packed dealer for fishermen) (nilai hasil analisis, 5,8).

\section{KESIMPULAN DAN SARAN}

\section{Kesimpulan}

1. Laut Banda dan PulauAmbon berpotensi menghasilkan sumber daya yang sangat besar. Hasil tangkapan yang telah dicapai 444,5 ton per bulan untuk ikan pelagis kecil dan 183,2 ton per bulan untuk ikan pelagis besar adalah baru merupakan $59 \%$ dari potensi lestarinya. Dengan demikian, usaha perikanan pukat cincin sangat terbuka untuk dikembangkan.

2. Usaha perikanan pukat cincin di Maluku Tengah dipengaruhi oleh faktor-faktor internal dan ekternal. Hasil analisis menunjukkan bahwa faktor keterampilan dan kegiatan penangkapan memperoleh nilai (score) yang cukup tinggi, dan hal ini merupakan kekuatan. Sementara kelemahan yang mengganggu usaha adalah sering terjadinya konflik, kelangkaan bahan bakar minyak, rendahnya pengetahuan, dan keterampilan teknis operasional. Harga bahan bakar minyak yang yang tidak pernah turun, bahkan makin meningkat menyebabkan pengeluaran biaya operasional yang besar. 
3. Matriks external factor evaluation merupakan cakupan dari peluang (opportunity $=0$ ) dan ancaman (threats $=\mathrm{T}$ ). Pembobotan terhadap faktor-faktor (peluang dan ancaman) yang dianalisis dalam matriks external factor evaluation menunjukkan bahwa faktor peluang investor menanamkan modal dan harga bahan bakar minyak mendapatkan nilai 4 (sangat kuat). Strategi alternatif dalam sistem usaha perikanan pukat cincin di perairan Laut Banda dan Pulau Ambon adalah diversifikasi produk pengolahan perikanan, yang dalam analisis memperoleh nilai 7,15 (tertinggi).

\section{Saran}

Diharapkan perhatian dari lembaga pemerintahan dan instansi-instani terkait melihat ini sebagai peluang kebangkitan Maluku dari keterpurukkan. Perlu dibuat suatu kelembagaan yang dapat memperkuat hubungan dan kerja sama antara Pemerintah Daerah dengan Dinas Perikanan dan Kelautan setempat dengan Pusat Pelabuhan Nusantara, dalam mengatur serta mengelola situasi dan kondisi di Maluku agar tercipta kepastian hukum sehingga tercipta situasi usaha yang kondusif.

\section{DAFTAR PUSTAKA}

Barus, H. R., Badruddin, \& Naamin N. 1991. Prosiding Forum II Perikanan. Sukabumi 18-21 Juni 1991. Jakarta. Departemen Pertanian. Badan Penelitian dan Pengembangan Pertanian. Pusat Penelitian dan Pengembangan Perikanan. 91-105 $p$.

Badan Riset Kelautan dan PerikananLembaga Ilmu Pengetahuan Indonesia. 2001. Kerja Sama Badan Riset Kelautan dan Perikanan dan Pusat Penelitian dan
Pengembangan Oceanologi Lembaga IImu-Lembaga IImu Pengetahuan Indonesia.

Dinas Perikanan dan Kelautan Propinsi Maluku. 2005. Laporan Tahunan Statistik Perikanan Tahun 2004. Ambon.

Dinas Perikanan dan Kelautan Propinsi Maluku. 2006. Laporan Tahunan Statistik Perikanan Tahun 2005 Ambon.

Namsa, D. 2006. Analisis Pengembangan Perikanan Soma Pajeko (mini purse seine) di Perairan Tidore. Tesis.

Khaled, M. S. 1986. Production Technologi of the Riverine Fisheries in Bangladesh dalam Small-Scale Fisheries in Asia: Sosioeconomic Analysis And Policy. p. 113-120.

Latumeten, J. 1984. Perikanan bubu di daerah Latuhalat Kodya Ambon Provinsi Maluku. Skripsi.

Mattjik, A. A. \& Sumertajaya. 2000. Perancangan Percobaan dengan Aplikasi SAS dan Minitab. Jilid I. Institut Pertanian Bogor. Press. Bogor. 326 p.

Panayotou, T. 1986. Small Scale Fisheries in Asia. Sosio Economic Analysis and Policy. $283 \mathrm{p}$.

Rafni, Y. N. 1999. Studi Stimulasi Gerakkan Vertikal Kapal Purse Seine terhadap Gelombang Reguler Following Seas.

Rangkuti, F. 2004. Analisis SWOT teknik membedah kasus bisnis. Reorientasi Konsep Perencanaan Strategis untuk Menghadapi Abad 21. Penerbit PT. Gramedia Pustaka Utama. Jakarta. 188 p. 
J. Kebijak. Perikan. Ind. Vol.2 No.1 Mei 2010: 57 - 70

Soekartawi, N. S. 1994. Teori Ekonomi Produksi dengan Pokok Bahasan Analisis Fungsi Cob-Douglass. PT. Raja Grafindo Persada. 257 p.
Salusu, J. 1996. Pengambilan Keputusan Strategi untuk Organisasi Publik dan Organisasi Non Profit. Penerbit PT. Grasindo. Jakarta. 358 p. 